\title{
ANTROPOGEMORFOLOGIA E PROBLEMÁTICA EROSIVA EM ÁREA RURAL DEGRADADA, MARABÁ PAULISTA (SP)
}

\author{
Felipe Augusto Scudeller Zanatta ${ }^{(\mathrm{a})}$, Cenira Maria Lupinacci ${ }^{(\mathrm{b})}$, Marcos Norberto Boin $^{(\mathrm{c})}$, \\ Rodrigo Braga Moruzzi ${ }^{(\mathrm{d})}$
}

\author{
(a) Departamento de Planejamento, Instituto de Geociências e Ciências Exatas, Universidade Estadual Paulista, \\ felipeasz@homail.com \\ (b) Departamento de Planejamento, Instituto de Geociências e Ciências Exatas, Universidade Estadual Paulista, \\ cenira@rc.unesp.br \\ ${ }^{(\mathrm{c})}$ Departamento de Pós-Graduação em Geografia, Universidade Federal da Grande Dourados, \\ boinmar@hotmail.com \\ (d) Departamento de Planejamento, Instituto de Geociências e Ciências Exatas, Universidade Estadual Paulista, \\ rmoruzzi@rc.unesp.br
}

\section{EIXO: SISTEMAS GEOMORFOLÓGICOS: ESTRUTURAS, DINÂMICAS E PROCESSOS}

\begin{abstract}
Resumo
A erosão do solo representa um problema significativo nas áreas rurais do país, uma vez que causa prejuízos e perdas de recursos naturais, área agricultável e produtividade dos solos. Considerando a problemática, buscou-se nesse artigo compreender a dinâmica erosiva avaliando as correlações existentes entre as mudanças nas feições geomorfológicas e o uso da terra, ao longo de cinquenta anos, em área rural degradada, no município de Marabá Paulista (SP). Como resultado, identificou-se a correlação positiva de forte à perfeita entre as pastagens e os processos erosivos e destes, também, com os terraços agrícolas e bacias de contenção, uma vez que a infiltração abastece a voçoroca existente na área, aumentando o fluxo de água no talvegue e promovendo desbarrancamentos nas laterais e cabeceira dessa forma erosiva.
\end{abstract}

Palavras-chave: Dinâmica erosiva; Cartografia retrospectiva; Coeficiente de Correlação de Pearson (CCP); Ação antrópica.

\section{Introdução}

A erosão do solo representa um problema de dimensões globais, devido, sobretudo, ao uso inadequado dos terrenos para fins agropastoris. De acordo com estudo da Food and Agriculture Organization of the United Nations (FAO, 2015), 33\% dos solos em uso no mundo encontram-se degradados. Nessas áreas, destinam-se recursos para controlar o processo, no entanto, quando não se compreende o comportamento do fenômeno, mesmo com investimento em distintas técnicas, por vezes, acaba-se por intensificar a erosão, resultando em mais prejuízos.

O fenômeno erosivo constitui-se em um processo da natureza que pode ocorrer independente da ação humana. A forma erosiva indica estado de desequilíbrio, provocado quando da alteração de um ou mais componentes do ambiente e no modo como os elementos se inter-relacionam, de maneira que a energia que entra no sistema encontre alterações em sua de dissipação. Nessa perspectiva, o desenvolvimento do processo erosivo indica a busca do sistema ambiente por um novo equilíbrio 
XVII Simpósio Brasileiro de Geografia Fisica Aplicada

I Congresso Nacional de Geografia Física

\section{OS DESAFIOS DA GEOGRAFIA FÍSICA NA FRONTEIRA DO CONHECIMENTO}

Instituto de Geociências - Unicamp

Campinas - SP

28 de Junho à 02 de Julho de 2017

dinâmico após a perturbação, ou seja, um novo arranjo entre os componentes do sistema que possibilite dissipação da energia sem provocar alterações funcionais, e, consequentemente, estruturais, cessando o efeito da erosão.

A ação humana, quando incompatível com as características naturais do ambiente em que se estabelece, proporciona o estado de desequilíbrio, uma vez que altera um ou mais elementos desconsiderando sua importância para organização daquele sistema.

No intuito de compreender a problemática erosiva, considerando a ação humana e a formação e desenvolvimento dos processos erosivos em uma perspectiva do tempo histórico, nesse artigo, foi selecionada como área de estudo uma bacia hidrográfica localizada na área rural do Município de Marabá Paulista, a Oeste do estado de São Paulo.

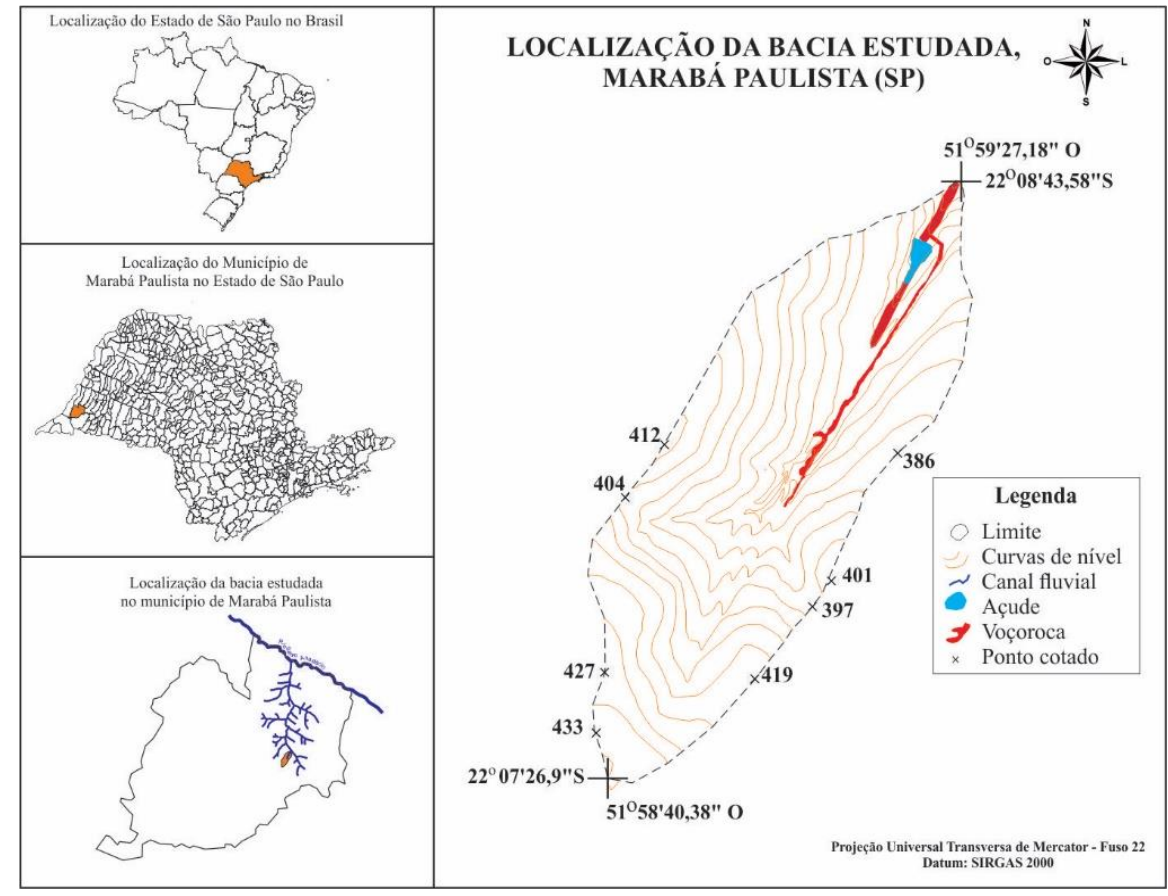

Figura 1: Localização da Bacia estudada

O objeto de estudo foi selecionado em virtude de um extenso processo de voçorocamento que dá origem a um canal antropogênico, o qual escoa no percurso de antiga estrada rural, situação que se registra com frequência em Marabá Paulista (SP)Assim, avalia-se o efeito das interferências antrópicas (uso da terra) e as técnicas conservacionistas utilizadas, na dinâmica erosiva da bacia estudada.

Localizada sobre litologias areníticas do Grupo Bauru, os solos da bacia estudada são predominantemente de textura arenosa em todo perfil (CARVALHO et al., 1997), submetidos a um clima tropical úmido, com chuvas intensas e/ou prolongadas, sobretudo na primavera e verão (BOIN, 2000). Inserida no contexto de ocupação do Oeste Paulista, iniciado no final do século XIX e início do século XX (MONBEIG, 1984), o uso da terra se estabeleceu de maneira predatória e descontextualizada em relação às especificidades do ambiente. A bacia em questão, desde a década de 
XVII Simpósio Brasileiro

de Geografia Física Aplicada

I Congresso Nacional

de Geografia Física
OS DESAFIOS DA GEOGRAFIA FÍSICA NA FRONTEIRA DO CONHECIMENTO

Instituto de Geociências - Unicamp

Campinas - SP

28 de Junho à 02 de Julho de 2017

60, não apresenta vegetação nativa, sendo, em sua totalidade, submetida à racionalidade econômica da produção agropecuária até os dias atuais.

Nessa área, mapeou-se, em escala 1: 10.000, as feições geomorfológicas, seguindo orientações de Tricart (1965), nos cenários de 1963, 1979 1997, 2010 e 2015. Nesses anos, também foram mapeados o uso e cobertura superficial da terra, de acordo com a proposta do Instituto Brasileiro de Geografia e Estatística (IBGE, 2006). Os mapeamentos foram realizados no programa ArcGis 9.2, por meio do qual levantou-se os dados quantitativos das feições geomorfológicas e do uso e cobertura superficial da terra. Esses dados, tabulados no programa Microsoft Excel ${ }^{\circledR}$, foram trabalhados estatisticamente através do Coeficiente de Correlação de Pearson (CCP), de modo a indicar o grau de relacionamento entre as variáveis quantificadas, procurando compreender a dinâmica erosiva e a organização funcional do sistema.

\section{Materiais e técnicas cartográficas}

O trabalho cartográfico iniciou-se com a digitalização das cartas topográficas desenvolvidas pelo Instituto Geográfico e Cartográfico do Estado de São Paulo (IGC), em escala 1: 10.000, extraindo das Folhas SF-22-Y-B-II-1-SO-A, SF-22-Y-B-I-2-SE-B, SF-22-Y-B-II-1-NO-E, SF-22-Y-B-I-2-NE-F, os dados de topografia, como curvas de nível e os pontos cotados, com seus respectivos valores altimétricos, vetorizados no programa ArcGis 9.2. Todos os mapeamentos foram convertidos para a escala da carta base, 1: 10.000 .

Posteriormente as fotografias aéreas dos anos de 1963 (Levantamento Fotogramétrico do Estado de São Paulo), escala 1: 25.000, 1979 (Terrafoto S.A. - Atividades de Aerolevantamentos, 1978/9), escala 1: 20.000, e 1997 (Aerolevantamento Presidente Venceslau e áreas correlatas), 1: 35.000, foram trabalhadas em estereoscopia digital, no programa StereoPhotoMaker, enquanto a fotografia aérea de 2010 (Projeto de atualização cartográfica do Estado de São Paulo - Mapeia São Paulo), em escala 1:10.000, e a imagem orbital do satélite Quickbird 2013 foram avaliadas por fotointerpretação e reambuladas de campo.

Para as cartas de geomorfologia utilizou-se a metodologia de Tricart (1965), com algumas adaptações de simbologias de Verstappen e Zuidan (1975), identificando: formas erosivas (formas que indicam erosão laminar, sulcos, ravina e voçoroca); feições de drenagem (fundo de vale plano); e modelado antrópico (canal antropogênico, terraços agrícolas, bacias de contenção, açudes e estradas rurais). Já para os dados de uso e cobertura superficial da terra, utilizaram-se as orientações de IBGE (2006), mapeando as áreas com: reflorestamento; silvicultura; cultura temporária; pasto; pasto sujo e vegetação de área úmida.

Após a identificação e mapeamento das feições geomorfológicas e do uso e cobertura superficial da terra nos cinco cenários avaliados, essas informações foram levantadas de forma quantitativa, sendo os 
XVII Simpósio Brasileiro

de Geografia Física Aplicada

I Congresso Nacional

de Geografia Física
OS DESAFIOS DA GEOGRAFIA FÍSICA NA FRONTEIRA DO CONHECIMENTO

Instituto de Geociências - Unicamp

Campinas - SP

28 de Junho à 02 de Julho de 2017

dados de uso da terra trabalhados em porcentagem de área; já os dados geomorfológicos foram avaliados de acordo com sua natureza espacial, a saber: marcas que indicam erosão laminar, voçoroca, terraços agrícolas e açudes em área, em \%; bacias de contenção, sulcos e ravinas em número; estrada rural, canal fluvial com fundo de vale plano e canal antropogênico em extensão, em km.

Esses dados quantitativos foram analisados através do Coeficiente de Correlação de Pearson (CCP). Para tanto, no programa Microsoft Excel, elaborou-se uma tabela contendo nas colunas os anos, os dados de uso da terra e de geomorfologia, enquanto as linhas a área, número ou extensão das variáveis em cada cenário analisado (1963, 1979, 1997, 2010 e 2015). Os resultados foram marcados com cores que variam de verde (intensidade de correlação positiva), vermelho (intensidade de correlação negativa) e branco (correlação nula).

Ao final, foi realizada a remoção dos dados que não apresentavam significância espacial, como, por exemplo: as correlações entre informações de uso da terra, optando-se, ainda, pela exclusão das informações de silvicultura e reflorestamento que abrangem áreas muito pequenas. Como também descriminadas as informações que oscilam em faixas diferentes ao longo dos anos, analisadas de forma separada.

\section{Resultados e discussão}

A área estudada, desde 1963 não apresenta vegetação do tipo nativa, portanto, desde o primeiro ano analisado, a bacia encontra-se em sua totalidade vinculada à racionalidade estritamente econômica para produção agrícola, sobretudo para pastagem, presente na maioria da bacia em todos os cenários, com destaque para 1979 e 1997 (Tabela 1).

Tabela 1: Uso e cobertura superficial da terra ao longo dos cenários analisados. Área, em \%

\begin{tabular}{lrrrrrr} 
Ano & Reflorestamento & Silvicultura & $\begin{array}{r}\text { Cultura } \\
\text { temporária }\end{array}$ & Pasto & $\begin{array}{r}\text { Pasto } \\
\text { sujo }\end{array}$ & $\begin{array}{r}\text { Vegetação de } \\
\text { área úmida }\end{array}$ \\
\hline $\mathbf{1 9 6 2}$ & 0,00 & 4,01 & 30,03 & 65,83 & 0,00 & 0,00 \\
$\mathbf{1 9 7 9}$ & 0,00 & 0,00 & 0,00 & 100 & 0,00 & 0,00 \\
$\mathbf{1 9 9 7}$ & 0,30 & 0,00 & 0,00 & 96,19 & 2,67 & 0,00 \\
$\mathbf{2 0 1 0}$ & 0,63 & 0,00 & 51,17 & 44,11 & 3,39 & 0,18 \\
$\mathbf{2 0 1 5}$ & 0,63 & 0,00 & 51,17 & 42,11 & 5,39 & 0,18 \\
\hline
\end{tabular}

Mudanças significativas ocorrem a partir de 2010, em que as empresas sucroalcooleiras se expandem para a região, arrendando metade dos terrenos da bacia para cultivo de cana-de-açúcar, apresentada como cultura temporária na Tabela 1, a qual passa a ocupar 51,17\% em 2010. Este montante, em campo no ano de 2015, constatou-se que, devido ao término da concessão antes do período da safra, encontra-se abandonado, sem manejo adequado, com a cana-de-açúcar queimada, utilizada como pasto. 
XVII Simpósio Brasileiro

de Geografia Fisica Aplicada

I Congresso Nacional

de Geografia Física

\section{OS DESAFIOS DA GEOGRAFIA FÍSICA NA FRONTEIRA DO CONHECIMENTO \\ Instituto de Geociências - Unicamp \\ Campinas - SP \\ 28 de Junho à 02 de Julho de 2017}

$\mathrm{Na}$ condição de toda cobertura superficial dos terrenos determinada pela ação antrópica desde o primeiro ano avaliado, identificaram-se formas erosivas em estágios de desenvolvimento avançado em todos os cenários, as quais aumentaram em área e número ao longo dos anos (Tabela 2).

Tabela 2: Feições geomorfológicas dos cenários analisados

\begin{tabular}{l|rrrrr} 
& $\mathbf{1 9 6 2}$ & $\mathbf{1 9 7 9}$ & $\mathbf{1 9 9 7}$ & $\mathbf{2 0 1 0}$ & $\mathbf{2 0 1 5}$ \\
\hline $\begin{array}{l}\text { Marcas que indicam erosão laminar } \\
\text { (área, em \%) }\end{array}$ & 13,08 & 74,82 & 97,77 & 82,60 & 98,00 \\
Sulco (número) & 9,00 & 13,00 & 33,00 & 43,00 & 54,00 \\
Ravina (número) & 7,00 & 17,00 & 17,00 & 65,00 & 65,00 \\
Voçoroca (área, em \%) & 0,32 & 1,06 & 1,04 & 1,26 & 1,37 \\
Canal fluvial com fundo de vale & & & & & \\
plano (extensão, km) & 0,55 & 0,56 & 0,57 & 0,53 & 0,53 \\
Canal antropogênico (extensão, km) & 0,00 & 0,56 & 0,71 & 0,89 & 1,11 \\
Terraços agrícolas (área, em \%) & 0,00 & 0,00 & 49,00 & 79,28 & 79,28 \\
Bacias de contenção (número) & 0,00 & 0,00 & 0,00 & 57,00 & 57,00 \\
Estrada rural (extensão, km) & 5,01 & 5,25 & 5,25 & 6,86 & 6,86 \\
Açude (área, em \%) & 0,00 & 0,00 & 0,47 & 0,47 & 0,47 \\
\hline
\end{tabular}

De 1997 para 2010, embora diversas técnicas conservacionistas tenham sido implementadas para conter os processos erosivos de vertentes, observa-se um aumento significativo destas, sobretudo em meio às pastagens (Figura 2).

Na voçoroca 1, que se desenvolve em canal com fundo plano desde o primeiro ano analisado, o médio curso do canal foi represado em 1997 para conter o fluxo de água, e, consequentemente, o processo erosivo. Como efeito, nos anos seguintes, 2010 e 2015, constata-se a colonização por vegetação de área úmida no talvegue da forma erosiva, ao mesmo tempo que surgem ravinas e sulcos na cabeceira e em suas margens, a jusante e montante do represamento. Já na voçoroca 2, identificada a partir do segundo ano analisado, em 1979, tem seu escoamento direcionado à estrada rural, originando um canal antropogênico. Esse canal passa a captar toda água que escoa da alta e média bacia e das vertentes à L da baixa bacia, de modo que a erosão se ramifica com maior intensidade nas vertentes a $\mathrm{L}$, onde predomina o pasto desde 1979, enquanto nas margens a O, a erosão evolui com menor intensidade, devido, sobretudo, ao cercamento das margens das ravinas e voçorocas, de dezenas de bacias de contenção em setores onde ocorrem sulcos e dos reparos periódicos nos terraços agrícolas em área de cultivo de cana-de-açúcar (Figura 2). 


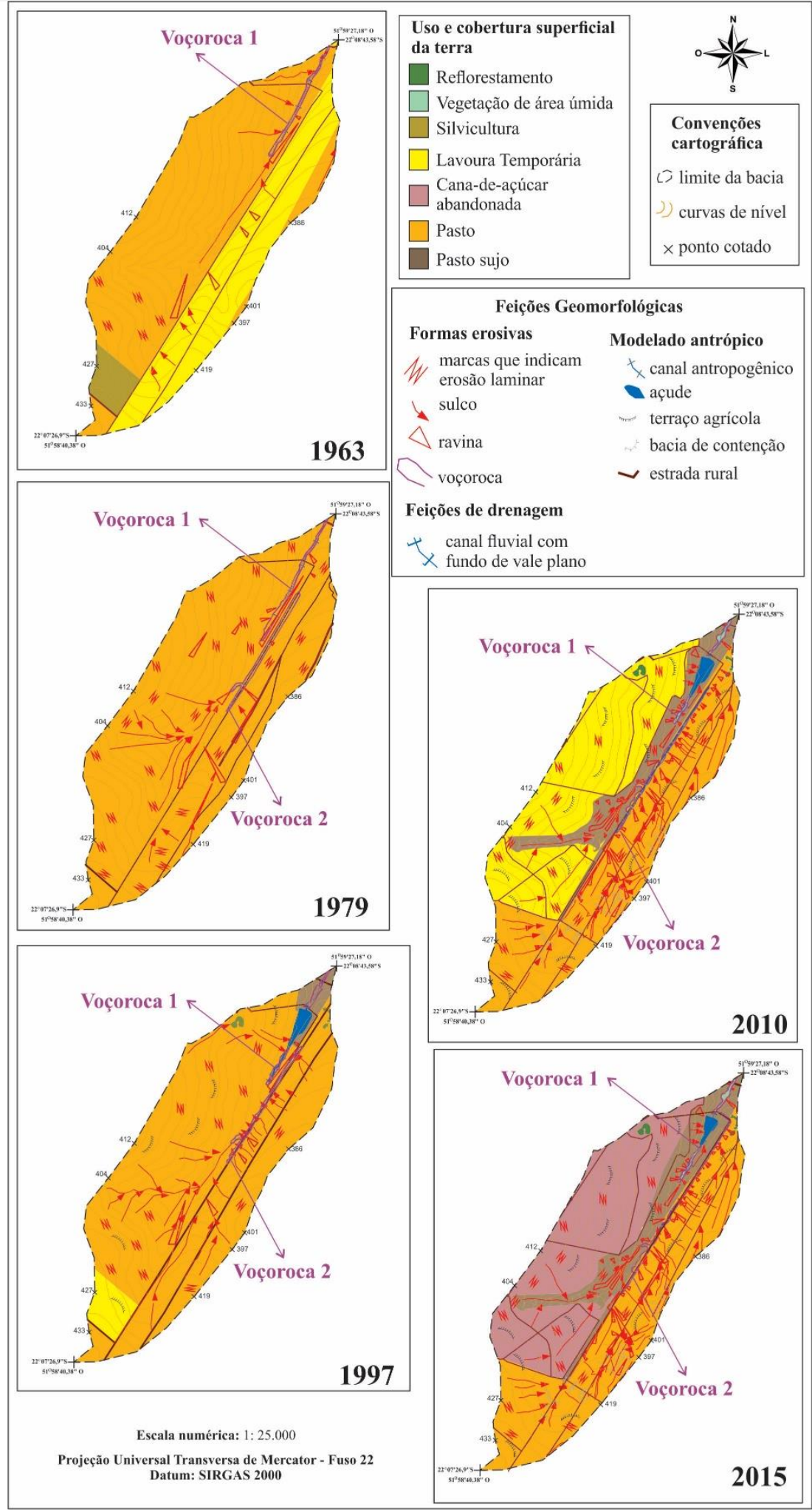

Figura 2: Uso e cobertura superficial da terra e feições geomorfológicas nos cenários de 1963, 1979, 1997, 2010, 2015 
XVII Simpósio Brasileiro

de Geografia Física Aplicada

I Congresso Nacional

de Geografia Física

\section{OS DESAFIOS DA GEOGRAFIA FÍSICA NA FRONTEIRA DO CONHECIMENTO \\ Instituto de Geociências - Unicamp \\ Campinas - SP \\ 28 de Junho à 02 de Julho de 2017}

Dessa forma, ao longo das mudanças apresentadas nos cenários avaliados, constatou-se a intensidade de correlação positiva entre o uso da terra, as técnicas conservacionistas e as formas erosivas (Tabela $3)$.

Tabela 3: Coeficiente de Correlação de Pearson (CCP) entre variáveis de uso da terra e geomorfologia ao longo dos cenários de 1963, 1976, 1997, 2010 e 2015
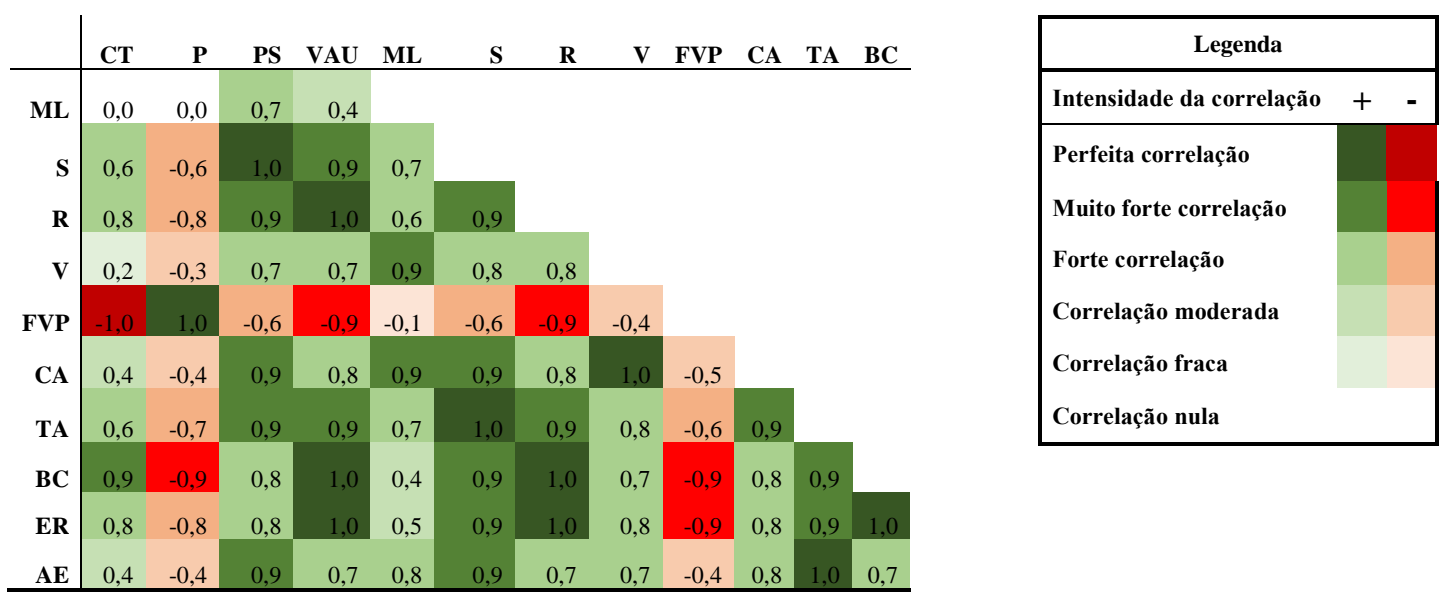

Legenda: cultura temporária (CT); pasto (P); pasto sujo (PS); vegetação de área úmida (VAU); marcas que indicam erosão laminar (ML); sulcos (S); ravina (R); voçoroca $(\mathrm{V})$; canal fluvial com fundo de vale plano (FVP); canal antropogênico (CA); terraço agrícola (TA); bacias de contenção (BC); estrada rural (ER) e açude (AE).

Quanto as mudanças promovidas na cobertura superficial no ano de 2010, constatou-se que 51,17\% das áreas com pasto foram destinadas ao cultivo de cana-de-açúcar (Tabela 1). Em relação à essa cobertura, verifica-se a correlação nula com as marcas que indicam erosão laminar (Tabela 3), uma vez que durante o cultivo são realizados constantes reparos dos terraços agrícolas, no entanto, a intensidade de correlação é positiva com os fenômenos lineares, sendo correlação forte com os sulcos e ravinas e fraca com a voçoroca (Tabela 3). Como observado na Figura 2, o processo não atinge nível de ravinamento sob essa cobertura, mas constata-se presença de sulcos e marcas que indicam erosão laminar, estágios iniciais do processo erosivo. Isso ocorre devido à manutenção constante dos terraços agrícolas, uma vez a cana-de-açúcar oferta pouca proteção ao solo no período de entressafra, momento que coincide com as primeiras chuvas após o inverno. Assim, segundo pesquisas já divulgadas (LEPSCH et al., 1983; MENDES, 1993) essa cobertura é menos eficiente que as gramíneas utilizadas para pastagens, de modo que muitas das feições que surgem durante os períodos chuvosos são corrigidas com carreadores, impossibilitando que essas sejam cartografadas.

A intensidade da correlação negativa entre o pasto e todas as formas erosivas decorre da redução dessa cobertura superficial a partir de 2010, enquanto as formas erosivas continuam aumentando, embora, em sua maioria, sejam em áreas de pasto. Assim, ao avaliar a correlação entre as pastagens e as formas erosivas, nos três primeiros anos (1963, 1979 e 1997), em que o pasto predomina e as voçorocas surgem, aferiu-se a perfeita correlação com as formas erosivas mais desenvolvidas (ravinas e 
XVII Simpósio Brasileiro

de Geografia Física Aplicada

I Congresso Nacional

de Geografia Física

\section{OS DESAFIOS DA GEOGRAFIA FÍSICA NA FRONTEIRA DO CONHECIMENTO}

Instituto de Geociências - Unicamp

Campinas - SP

28 de Junho à 02 de Julho de 2017

voçorocas), muito forte correlação com marcas de erosão laminar e moderada correlação com os sulcos (Tabela 4).

Tabela 4: Coeficiente de Correlação de Pearson (CCP) entre pasto e formas erosivas nos cenários de 1963,1979 e 1997

\begin{tabular}{r|rrrr} 
& $\begin{array}{r}\text { Marcas que indicam } \\
\text { erosão laminar }\end{array}$ & Sulco & Ravina & Voçoroca \\
\hline Pasto & 0,9 & 0,5 & 1,0 & 1,0 \\
\hline
\end{tabular}

\begin{tabular}{|l|}
\hline \multicolumn{2}{|c|}{ Legenda } \\
\hline Intensidade de correlação
\end{tabular}$\quad+$

Tais dados indicam que o pastoreio excessivo e contínuo em solos de textura arenosa promove o desencadeamento de processos areolares e lineares nas vertentes, de modo que o fenômeno, ainda, se desenvolva com intensidade, provocando na destruição da vertente.

A mesma situação de intensidade da correlação negativa ocorre ente os canais fluviais com fundo de vale plano e as demais variáveis, uma vez que essa feição de drenagem, em 1997, é reduzida em extensão quando ocorre o represamento no médio curso do canal, na medida que todas as demais variáveis aumentaram nos anos seguintes, exceto o pasto, com que apresenta correlação forte. Ao verificar a correlação existente entre as formas erosivas e o fundo de vale plano nos anos anteriores ao represamento, 1963 e 1979, identificou-se a perfeita correlação positiva entre as variáveis, uma vez que todo o percurso desse canal se encontrava no interior da voçoroca e este processo se ramificou em ravinas e sulcos, dinamizando os processos erosivos nas vertentes (Tabela 5).

Tabela 4: Coeficiente de Correlação de Pearson (CCP) entre canal fluvial com fundo de vale plano e formas erosivas nos cenários de 1963 e 1979

\begin{tabular}{l|cccc} 
& $\begin{array}{c}\text { Marcas que indicam } \\
\text { erosão laminar }\end{array}$ & Sulco & Ravina & Voçoroca \\
\hline $\begin{array}{l}\text { Canal fluvial com fundo } \\
\text { de vale plano }\end{array}$ & 1 & 1 & 1 & 1 \\
\hline
\end{tabular}

\begin{tabular}{|l|}
\hline \multicolumn{1}{|c|}{ Legenda } \\
\hline $\begin{array}{l}\text { Intensidade da } \\
\text { correlação }\end{array}$ \\
\hline $\begin{array}{l}\text { Perfeita } \\
\text { correlação }\end{array}$ \\
\hline
\end{tabular}

Em 1997 inicia-se o uso de terraços agrícolas em meio às pastagens e a construção de um açude no médio curso do canal em fundo plano com voçorocamento. No entanto, nos anos que seguem, 2010 e 2015, mesmo com as mudanças na atividade agropastoril, o cercamento das voçorocas e ravinas nas vertentes a $\mathrm{O}$, o aumento dos terraços agrícolas para 79,28\% dos terrenos da bacia e o uso de cinquenta e sete bacias de contenção em áreas que desenvolvem sulcos, houve concomitante ampliação de todos processos erosivos (Tabela 2), sendo as intensidades de correlação positivas entre as técnicas utilizadas e todas as formas erosivas (Tabela 3). 
XVII Simpósio Brasileiro

de Geografia Fisica Aplicada

I Congresso Nacional

de Geografia Física

\section{OS DESAFIOS DA GEOGRAFIA FÍSICA NA FRONTEIRA DO CONHECIMENTO \\ Instituto de Geociências - Unicamp \\ Campinas - SP \\ 28 de Junho à 02 de Julho de 2017}

Embora os terraços agrícolas e as bacias de contenção tenham teoricamente a função de conter o fluxo de água e, portanto, impedir o desenvolvimento dos processos erosivos nas vertentes, quando da presença da voçoroca, tais técnicas apresentam efeito contrário, uma vez que aumentando a infiltração de água, em solos de textura arenosa em todo perfil, o dinamiza a ação erosiva através de desbarrancamentos laterais e na cabeceira, com aumento de fluxo de água no talvegue da forma erosiva. Essa evolução da voçoroca desestabiliza os terrenos, com os solos desgastados pelo uso contínuo, aumentando o número das demais feições erosivas (sulcos e ravinas) nas vertentes (tabela 2). Esse processo foi aferido nas mudanças ocorridas nos dois últimos anos analisados: no cenário de 2010, a voçoroca que atinge a estrada rural, originando um canal antropogênico, não tinha força suficiente para escoar até o canal fluvial com fundo plano a jusante, infiltrando-se no solo arenoso em meio ao percurso; enquanto no cenário de 2015 ocorre aumento significativo do fluxo de água, de modo a escoar por toda estrada até atingir o canal a jusante do açude (Figura 3). Cabe destacar, que no dia 18 de outubro de 2016, data da fotografia 2 (Figura 3), as condições climáticas eram de um período seco.

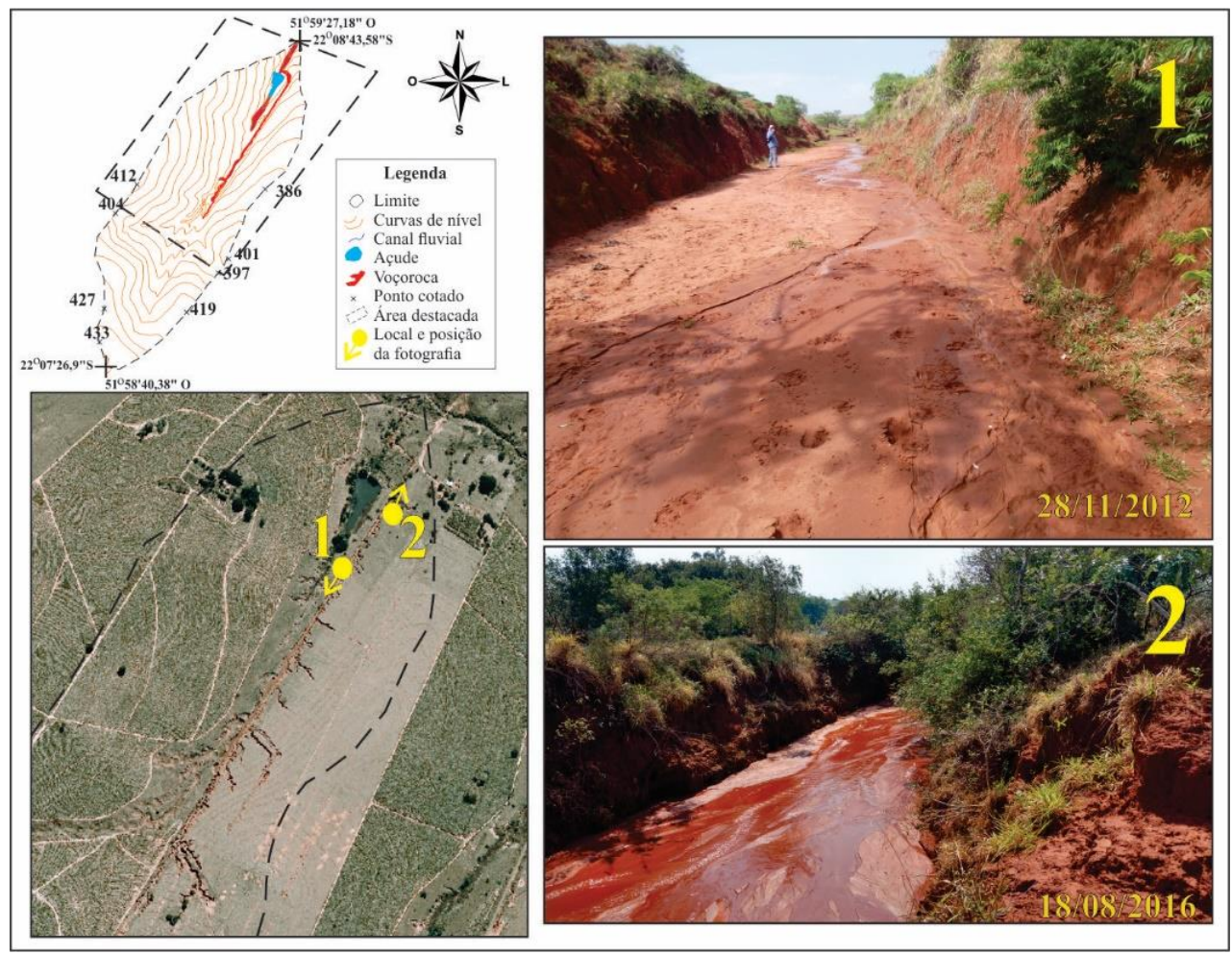

Figura 3: Fluxo de água na estrada rural atingida por voçorocamento em 28 de novembro de 2012 (1) e 18 de outubro de 2016 (2)

A fragilização dos solos, com o uso contínuo para pastoreio, que compacta os horizontes superficiais e dinamiza o desbarrancamento das formas lineares nas vertentes a L, e a queimada da cana-de-açúcar abandonada, que contribui para desestruturação dos horizontes superficiais nas vertentes a $\mathrm{O}$, aliadas 
XVII Simpósio Brasileiro

de Geografia Física Aplicada

I Congresso Nacional

de Geografia Física
OS DESAFIOS DA GEOGRAFIA FÍSICA NA FRONTEIRA DO CONHECIMENTO

Instituto de Geociências - Unicamp

Campinas - SP

28 de Junho à 02 de Julho de 2017

ao aumento de fluxo de água no talvegue da erosão, promovido pelas técnicas conservacionistas, contribuem para que o ambiente continue em estado de desequilíbrio.

\section{Considerações finais}

Os dados demonstram que as técnicas conservacionistas utilizadas para controlar o fenômeno erosivo, em uma bacia com dois processos de voçorocamento, contribuíram para potencializar a dinâmica erosiva na área, haja visto que o aumento dos terraços agrícolas e das bacias de contenção não reduziram o fenômeno, mas os intensificaram, promovendo o aumento do fluxo de água no talvegue da voçoroca e, consequentemente, o desenvolvimento dos processos lineares nas vertentes, principalmente à L em que o superpastoreio dos terrenos fragilizam os solos. Assim, a compreensão parcial do fenômeno acarreta em prejuízos, tanto na perda de recursos naturais, refletindo na diminuição da área agricultável, como de investimentos destinados a implementação de técnicas que não contribuem para conter o processo.

Como limitação do uso do Coeficiente de Correlação de Pearson (CCP) para análise junto a cartografia geomorfológica retrospectiva, constatou-se que algumas variáveis oscilam de forma distinta, não apresentando um comportamento linear ao longo do tempo, de modo que as feições erosivas tenham intensidade de correlação em intervalos negativos com o pasto, embora seja sobre predomínio desta cobertura que se desenvolvem as duas voçorocas presentes na bacia, em 1963 e 1979, e, embora reduzida a área em 2010 e 2015, seja nas vertentes a L em a voçoroca se ramifique com maior intensidade em sulcos e ravinas. Ademais, dada a natureza de sua formulação, a correlação medida entre pares de atributos quantitativos discretos limita a avaliação multivariada, característica de sistemas complexos.

\section{Bibliografia}

BOIN, M. N. Chuvas e erosão no Oeste Paulista: uma análise climatológica aplicada. Rio Claro: UNESP, 2000, 246p. Tese (Doutorado) - Programa de Pós-Graduação em Geociências e Meio Ambiente, Instituto de Geociências e Ciências Exatas, Universidade Estadual Paulista, Rio Claro, 2000.

CARVALHO, W. A. (coord.). Levantamento semidetalhado dos solos da bacia do rio Santo Anastácio-SP. Presidente Prudente, São Paulo: FCT-UNESP, 1997, vol. I e vol. II.

FOOD AND AGRICULTURE ORGANIZATION OF THE UNITED NATIONS (FAO). Status of the World's

Soil Resources. Roma: Food and Agriculture Organization of the United Nations, 2015.

INSTUTO BRASILEIRO DE GEOGRAFIA E ESTATÍSTICA (IBGE). Manual técnico de uso da terra. Rio de Janeiro: IBGE, 2006. 
LEPSCH, I. F.; BELLINAZZI Jr., R.; ESPINDOLA, C. R. Manual para levantamento utilitário do meio físico e classificação de terras no sistema de capacidade de uso. $4^{\mathrm{a}}$ aproximação. Campinas: Sociedade Brasileira de Ciência do Solo, 1993.

MENDES, I. A. A dinâmica erosiva do escoamento pluvial na bacia do córrego Lafon - Araçatuba-SP. São Paulo: USP, 1993. Tese (Doutorado) - Programa de Pós-Graduação em Geografia (Geografia Física). Faculdade de Filosofia, Letras e Ciências Humanas, Universidade de São Paulo, São Paulo, 1993.

MONBEIG, P. Pioneiros e Fazendeiros de São Paulo. São Paulo: HUCITEC, 1984.

TRICART, J. Principles et méthodes de la géomorphologie. Paris: Maisson, 1965.

VERSTAPPEN, H. T.; ZUIDAN, R. A. ITC system of geomorphological survey. Netherlands: Manuel ITC Textbook, Vol. VII, Chapter VII, 1975. 